\title{
Characterization of the single-chain Fv-Fc antibody MBP10 produced in Arabidopsis alg3 mutant seeds
}

\author{
Maurice Henquet • Jochem Eigenhuijsen - Thamara Hesselink • \\ Holger Spiegel • Mariëlle Schreuder • Esther van Duijn • Jan Cordewener • \\ Ann Depicker · Alexander van der Krol · Dirk Bosch
}

Received: 12 October 2010/Accepted: 10 December 2010/Published online: 25 December 2010

(C) The Author(s) 2010. This article is published with open access at Springerlink.com

\begin{abstract}
ER resident glycoproteins, including ectopically expressed recombinant glycoproteins, carry so-called high-mannose type $\mathrm{N}$-glycans, which can be at different stages of processing. The presence of heterogeneous high-mannose type glycans on ER-retained therapeutic proteins is undesirable for specific therapeutic applications. Previously, we described an Arabidopsis alg3-2 glycosylation mutant in which aberrant $\mathrm{Man}_{5} \mathrm{GlcNAc}_{2}$ mannose type N-glycans are transferred to proteins. Here we show that the alg3-2 mutation reduces the N-glycan heterogeneity on ER resident glycoproteins in seeds. We compared the
\end{abstract}

Electronic supplementary material The online version of this article (doi:10.1007/s11248-010-9475-5) contains supplementary material, which is available to authorized users.

M. Henquet $(\bowtie) \cdot$ T. Hesselink · J. Cordewener .

D. Bosch

Business Unit Bioscience, Plant Research International

BV, Wageningen University and Research Centre,

Droevendaalsesteeg 1, 6700 AA Wageningen,

The Netherlands

e-mail: Maurice.Henquet@wur.nl

D. Bosch

Membrane Enzymology, Department of Chemistry, Utrecht University, Padualaan 8, 3584 CH Utrecht,

The Netherlands

J. Eigenhuijsen · M. Schreuder · A. van der Krol Wageningen University and Research Centre, Laboratory of Plant Physiology, Droevendaalsesteeg 1, 6700 AA

Wageningen, The Netherlands properties of a $\mathrm{scFv}-\mathrm{Fc}$, with a KDEL ER retention tag (MBP10) that was expressed in seeds of wild type and alg3-2 plants. N-glycans on these antibodies from mutant seeds were predominantly of the intermediate $\mathrm{Man}_{5} \mathrm{GlcNAc}_{2}$ compared to $\mathrm{Man}_{8} \mathrm{GlcNAc}_{2}$ and $\mathrm{Man}_{7} \mathrm{GlcNAc}_{2}$ isoforms on MBP10 from wild-type seeds. The presence of aberrant $\mathrm{N}$-glycans on MBP10 did not seem to affect MBP10 dimerisation nor binding of MBP10 to its antigen. In alg3-2 the fraction of underglycosylated MBP10 protein forms was higher than in wild type. Interestingly, the expression of MBP10 resulted also in underglycosylation of other, endogenous glycoproteins.

\author{
H. Spiegel \\ Plant Molecular Biology Fraunhofer IME, \\ Forckenbeckstrasse 6, 52074 Aachen, Germany \\ E. van Duijn \\ Biomolecular Mass Spectrometry and Proteomics Group \\ Utrecht University, Padualaan 8, 3584 CH Utrecht, \\ The Netherlands
}
A. Depicker
Department of Plant Systems Biology, VIB, 9052 Ghent, Belgium
A. Depicker
Department of Plant Biotechnology and Genetics,
Ghent University, 9052 Ghent, Belgium 
Keywords N-glycosylation - Recombinant antibody $\cdot$ Molecular farming $\cdot$ Arabidopsis

\section{Introduction}

Plants have a great potential as an expression system for therapeutic proteins: plant produced pharmaceuticals are much less likely to harbor human pathogens, production costs are relatively low and the production is easily scalable, while products can efficiently be harvested and stored (Fischer and Emans 2000; Fischer et al. 2000; Giddings 2001). Harvesting of pharmaceuticals from plants may be greatly facilitated by directing expression of therapeutic proteins to the specialized storage organs of plants (Peeters et al. 2001; Staub et al. 2000; Stoger et al. 2000; Van Droogenbroeck et al. 2007). Many of the potential therapeutic proteins, including antibodies, require specific post-translational modifications for correct biological functioning.

Core $\mathrm{N}$-glycan biosynthesis is similar in mammals and plants, but mammals and plants make different complex-type $\mathrm{N}$-glycans. These differences between mammalian and plant $\mathrm{N}$-linked glycan biosynthesis limit the application of therapeutic glycoproteins produced by plants since the plant produced proteins may not have the desired biological properties (Rayon et al. 1998). For instance, the plant specific xylose and fucose of plant complex glycan structures may trigger an immunogenic response in mammals, making these plant specific modifications potentially immunogenic to mammals (Bencurova et al. 2004). Several approaches are being pursued to optimize glycosylation in plants for pharmaceutical protein production. Plant $\mathrm{N}$-glycans can be extended by mammalian type sugars through the introduction of mammalian glycosyltransferases. Via such plants, antibodies with $\mathrm{N}$-glycans extended with $\beta 1$,4-galactose and even sialic acid were produced (Misaki et al. 2003; Fujiyama et al. 2001; Bakker et al. 2001; Palacpac et al. 1999; Strasser et al. 2009; Castilho et al. 2010). The synthesis of the potentially immunogenic fucose and xylose epitopes may also be avoided by inhibiting the expression of the responsible glycosyltransferases such as demonstrated in tobacco, duckweed and moss (Huether et al. 2005; Cox et al. 2006; Strasser et al. 2008).

Alternatively, processing of N-glycans on therapeutic proteins may be controlled by retention of the protein in the ER (Van Droogenbroeck et al. 2007; Ko et al. 2003). In this case processing will not proceed beyond $\mathrm{Man}_{7} \mathrm{GlcNAc}_{2}$ type glycans, since the enzymes involved in further $\mathrm{N}$-glycan modification are located in the downstream Golgi compartments. However, also the presence of such high-mannose type glycans on plant produced and ER-retained therapeutic proteins may be undesirable for specific molecules, for example because they may contribute to a higher clearance rate of antibodies in mammalian hosts (Wright and Morrison 1998; Bardor et al. 2003; Ko et al. 2003). Recently we identified ALG3 gene from Arabidopsis thaliana as the Dol-PMan:Man ${ }_{5} \mathrm{GlcNAc}_{2}$-PP-Dol $\alpha 1,3$-mannosyl transferase which is involved in the build-up of dolichollinked high-mannose type glycans in the ER (Henquet et al. 2008). A homozygous T-DNA insertion mutant, alg3-2, with only very low levels of wild-type $A L G 3$ activity was identified. In this mutant, mostly truncated aberrant $\mathrm{Man}_{5} \mathrm{GlcNAc}_{2}$ instead of $\mathrm{Man}_{9} \mathrm{GlcNAc}_{2}$ glycans are transferred from dolichol to the glycoproteins. Consequently, most processing steps in the ER are skipped and ER resident glycoproteins in alg3-2 plants are almost uniformly modified by an abnormal $\mathrm{Man}_{5} \mathrm{GlcNAc}_{2}$ glycan (Henquet et al. 2008). Both the lack of high mannose glycans and the uniformity of protein glycan structures on ER-resident proteins in alg3-2 make this mutant an interesting host to test for improved quality of recombinant protein production in plants.

Previously, Arabidopsis plants have been described producing in seeds high levels of recombinant MBP10, a scFv-Fc directed against the Maltose Binding Protein, with a KDEL ER retention tag. $\mathrm{N}$-glycans present on these antibodies were predominantly of the $\mathrm{Man}_{8} \mathrm{GlcNAc}_{2}$ and $\mathrm{Man}_{7} \mathrm{GlcNAc}_{2}$ isoforms, while in addition significant amounts of the antibody chains were not glycosylated (Van Droogenbroeck et al. 2007). The MBP10 transgene was introduced through crossing into the alg3-2 mutant background and the properties of MBP10, as produced in wild-type and alg3-2 plants were compared. 


\section{Results}

$\mathrm{N}$-glycan profile in wild-type and alg3-2 mutant Arabidopsis seeds

The alg3-2 plant was shown to have only very low expression of the $A L G 3$ gene, which results in an altered $\mathrm{N}$-glycan profile on glycoproteins from leaves (Henquet et al. 2008). To determine whether this phenotype is also displayed in seeds of the alg3-2 mutant, the N-glycan profile of the total glycoprotein pool of wild-type and mutant Arabidopsis seeds was compared. Proteins were extracted from wild-type and alg3-2 seeds and $\mathrm{N}$-glycans were released by PNGase A treatment. Each N-glycan pool was analyzed by MALDI-TOF.

No $\mathrm{Man}_{9-6} \mathrm{GlcNAc}_{2}$ type glycans were detected in seeds of the mutant plants and instead particularly $\mathrm{Man}_{3} \mathrm{GlcNAc}_{2}, \mathrm{Man}_{4} \mathrm{GlcNAc}_{2}$ and some Man 5 Glc$\mathrm{NAc}_{2} \mathrm{~N}$-glycans accumulated. This analysis does not distinguish between the wild-type $\mathrm{Man}_{5} \mathrm{GlcNAc}_{2}$ and the aberrant $\mathrm{Man}_{5} \mathrm{GlcNAc}_{2}$ from the mutant glycosylation pathway (Supplemental Fig. 1), which contains $\alpha-1,2$ linked mannose residues (Henquet et al. 2008). The $\mathrm{Man}_{5} \mathrm{GlcNAc}_{2}$ glycans from the alg3-2 mutant with $\alpha-1,2$ linked mannoses are sensitive to $\alpha(1,2)$-mannosidase (+ManI) treatment. Therefore, the N-glycan pools were treated with $\alpha(1,2)$-mannosidase (Supplemental Table 1: +ManI). Results showed that in the ManI treated N-glycan fraction from wild-type all high mannose type $\mathrm{N}$-glycans had been trimmed, resulting in an increase of the ManIresistant $\mathrm{Man}_{5} \mathrm{GlcNAc}_{2}$ glycan pool (Supplemental Table 1), demonstrating the effectiveness of the ManI treatment. In the alg3-2 N-glycan fraction, the

Table 1 Relative amounts of N-glycans on MBP10 in wild-type and alg3-2 seeds

\begin{tabular}{lcc}
\hline Glycan structures & $\begin{array}{l}\text { Wild type } \\
\% \text { of total }\end{array}$ & $\begin{array}{l}\text { alg3-2 } \\
\% \text { of total }\end{array}$ \\
\hline Hex3GlcNAc2 & n.d. & n.d. \\
Hex4GlcNAc2 & n.d. & n.d. \\
Hex5GlcNAc2 & n.d. & 86.1 \\
Hex6GlcNAc2 & n.d. & n.d. \\
Hex7GlcNAc2 & 26.6 & 13.9 \\
Hex8GlcNAc2 & 73.4 & n.d. \\
Hex9GlcNAc2 & n.d. & n.d. \\
\hline
\end{tabular}

n.d. not detectable mannose type glycans were all trimmed to $\mathrm{Man}_{3}$ Glc$\mathrm{NAc}_{2}$, proving that the $\mathrm{Man}_{4} \mathrm{GlcNAc}_{2}$ and $\mathrm{Man}_{5} \mathrm{Glc}$ $\mathrm{NAc}_{2}$ contain $\alpha-1,2$ mannose residues and therefore are derived from the mutant pathway (Henquet et al. 2008).

The MALDI-TOF analysis suggests a lower level of complex type N-glycans in alg3-2 seeds compare to wild type (43.4 and $55.9 \%$, respectively), while on glycoproteins isolated from leaf tissue, the fraction of complex type $\mathrm{N}$-glycans is higher compared to wild type (62.2 vs. $48.1 \%$ respectively: see Henquet et al. 2008) To further investigate the level of complex glycosylation in alg3-2 seeds, proteins from wildtype, alg3-2 and from homozygous $\mathrm{cgl}$ mutant, which lack complex type glycans because of a defect in $\mathrm{N}$-acetylglucosaminyltransferase I (von Schaewen et al. 1993), were isolated from seeds and probed in an ELISA assay. The presence of glycoproteins with complex type glycans containing xylose and/or fucose can be detected with rabbit anti-horseradish peroxidase (HRP) antibodies, which are mostly directed against the complex type glycans. A difference of signal of proteins with $\mathrm{N}$-linked complex type glycans was observed in the homozygous alg3-2 mutant strain and wild-type plants (supplemental Fig. 2), indicating that in contrast to leaves, in seeds the mutation does affect the level of complex glycans on glycoproteins (Henquet et al. 2008).

\section{Characterization of N-glycans on MBP10}

in wild-type and $\operatorname{alg} 3-2$ seeds

MBP10 consists of a single chain $\mathrm{Fc}$ fused to an Fv directed against Maltose Binding Protein (MBP) and an additional KDEL sequence to retain the protein product in the ER. To determine the effect of the alg3-2 mutation on recombinant antibodies retained in the ER of seeds, we crossed wild-type Arabidopsis transgenic plants, homozygous for the MBP10 antibody expression construct (Van Droogenbroeck et al. 2007), with homozygous alg3-2 mutant plants. F1 progeny plants were allowed to self pollinate and F2 plants, homozygous for both the MBP10 expression construct and the alg3-2 mutation were selected as described in materials and methods. To compare the production of MBP10 in wild-type and alg3-2 seeds, proteins were isolated from the seeds, separated by SDS-PAGE under reducing conditions and visualized by Commassie blue staining. Both in wild-type and 
alg3-2 plants, similar high levels of scFv-Fc monomers migrated as major doublet bands at the expected molecular mass of $\sim 55 \mathrm{kDa}$ (Fig. 1, lanes 1 and 2), indicating that the alg3-2 mutation does not significantly affect the antibody accumulation level.

The two bands at about $55 \mathrm{kDa}$ reflect the glycosylated and unglycosylated form of the scFvFc monomers (Van Droogenbroeck et al. 2007). Indeed, in both samples, the scFv-Fc doublet collapsed to a single band after treatment with PNGase $\mathrm{F}$, with the same apparent molecular size as the lower band of the original doublet (Fig. 2, lanes 3 and 6). As complex type $\mathrm{N}$-glycans with Golgi specific modifications containing $\alpha 1,3$-linked fucose residues are resistant to PNGase F, the sensitivity of the upper band to PNGase F also indicates that the MPB10 is not decorated with complex type $\mathrm{N}$-glycans, in line with it being retained to the ER. Additional confirmation that the MBP10 in wild-type contains high mannose type $\mathrm{N}$-glycans came from its sensitivity to EndoH treatment (Fig. 2, compare lane 1 and 2). In contrast, N-glycans on MBP10 from alg3-2 were resistant to Endo $\mathrm{H}$, indicating that in alg3-2 seeds,

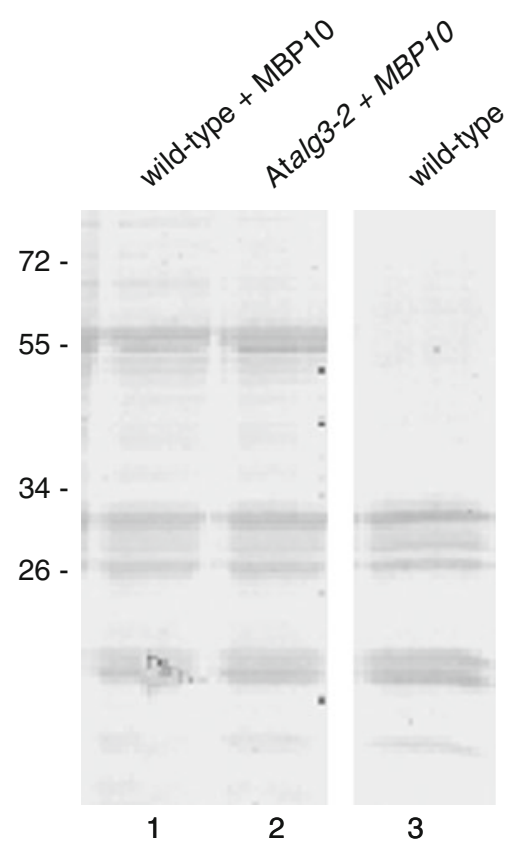

Fig. 1 Production of MBP10 in wild-type and alg3-2 seeds. Total seed protein fractions from wild-type expressing MBP10 (lane 1), alg3-2 expressing MBP10 (lane 2) and untransformed wild-type (lane 3) were separated by SDS-PAGE and visualized by Commassie staining the glycans on the antibodies are not of the same high mannose type. Because the N-glycans on MPB10 in alg3-2 seeds are sensitive to PNGase F but resistant to Endo $\mathrm{H}$ they are most likely derived from the mutant pathway in alg3-2 (Fig. 2, compare lane 5 and 6) in which an aberrant $\mathrm{Man}_{5} \mathrm{GlcNAc}_{2}$ glycan is transferred from lipid to protein.

In complementary experiments, the N-glycans on MBP produced in wild-type or alg3-2 seeds were analyzed by MALDI-TOF. The MBP10 protein from both wild-type and alg3-2 was isolated from a reducing denaturing SDS-PAGE gel, treated with trypsin and the peptide mixture was subjected to analysis by MALDI-TOF. In contrast to earlier LCMS analysis of N-glycans on MBP10 in wildtype (Van Droogenbroeck et al. 2007), no partial tryptic glycopeptides masses were detected in our analysis. Similar as to previously observed (Van Droogenbroeck et al. 2007), the most abundant glycans on scFv-Fc isolated from wild-type seeds were $\mathrm{Man}_{8} \mathrm{GlcNAc}_{2}$ and $\mathrm{Man}_{7} \mathrm{GlcNAc}_{2}$ (Table 1). The scFv-Fc glycopeptides from alg3-2 seeds were mostly modified by $\mathrm{Man}_{5} \mathrm{GlcNAc}_{2}$. However, also a significant pool was decorated with $\mathrm{Hex}_{7} \mathrm{GlcNAc}_{2}$ type glycans which could be wild type $\mathrm{Man}_{7} \mathrm{GlcNAc}_{2}$ or $\mathrm{Glc}_{2} \mathrm{Man}_{5} \mathrm{GlcNAc}_{2}$ glycans. This needs further investigation.

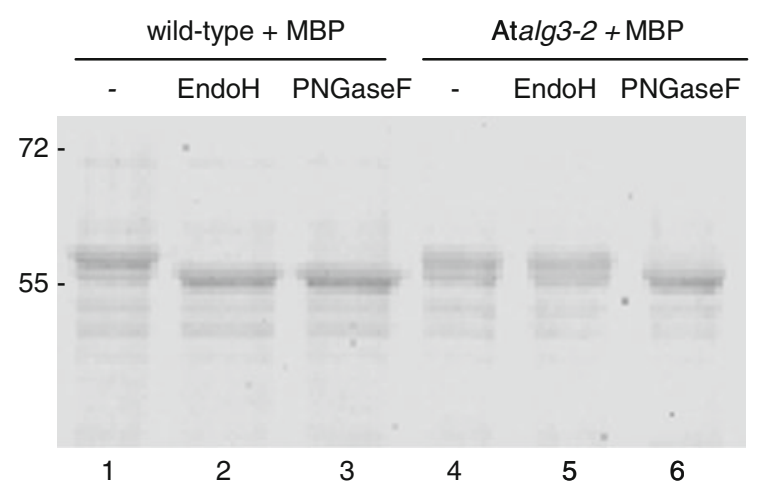

Fig. $2 N$-glycan analysis of MBP10 in wild-type and alg3-2 seeds. Isolated total seed protein fractions from wild-type expressing MBP10 (lane 1), alg3-2 expressing MBP10 (lane 4), before and after overnight incubation with EndoH (lanes 2 and 5) or PNGase F (lanes 3 and 6), were separated by SDS-PAGE, and visualized by Commassie staining 
Underglycosylation of MBP from wild type and $\operatorname{alg} 3-2$ seeds

To determine the amount of nonglycosylated MBP10 derived from wild type and alg3-2 seeds, the MBP10 protein was isolated with a Protein A column, deglycosylated with PNGase and treated with trypsin. The MBP10 peptide mixtures from wild type and alg3-2 were subjected LC-MS analysis. Since asparagine $(\mathrm{N})$ is converted to aspartic acid (D) in this PNGase F reaction, glycosylation sites can be identified by a mass increase of 1 Dalton. This mass difference can be measured by Q-TOF LC-MS and the ratio of $\mathrm{N}$ and $\mathrm{D}$ gives an indication for the ratio between non-glycosylated and deglycosylation of MBP10. From Fig. 2 it was already visible that both MBP10 variants contain nonglycosylated as well as glycosylated antibodies. The results show a significant increase in the amount of nonglycosylated MBP10 isolated from alg3-2 seeds $(31.0 \% \pm 2.3 \%)$ as compared to wild type seeds $(22.4 \% \pm 0.7 \%)$ (Fig. 3, Supplemental Fig. 3).

MBP10 expression in seeds affects glycosylation of endogenous glycoproteins

The fraction of underglycosylated MBP10 in both wild type and alg3-2 may suggest that the glycosylation capacity of the cells in developing seeds may not be able to cope with the elevated level of glycoprotein expression. To determine whether this effect of high heterologous MBP10 production levels on glycosylation also affects endogenous ER resident proteins, the glycosylation of protein disulfide isomerase (PDI) was investigated in wild-type and alg3-2 seeds from plants with or without seed specific MBP10 expression. Indeed, PDI showed no signs of underglycosylation in wild type, while underglycosylation was weak in wild-type + MBP10, stronger in alg3-2 and strongest in alg3-2 + MBP10 (Fig. 4). Apparently, the ectopic MBP10 expression in both wild type and alg3-2 causes competition for glycosylation activity, resulting in PDI underglycosylation in the ER. Glycan analysis showed that the glycans of PDI from wild type were cleaved by EndoH (data not shown), while the glycans on MBP10 from alg3-2 seeds were resistant to EndoH treatment, indicating that these are not normal high-mannose type glycans and therefore most likely derived from the mutant

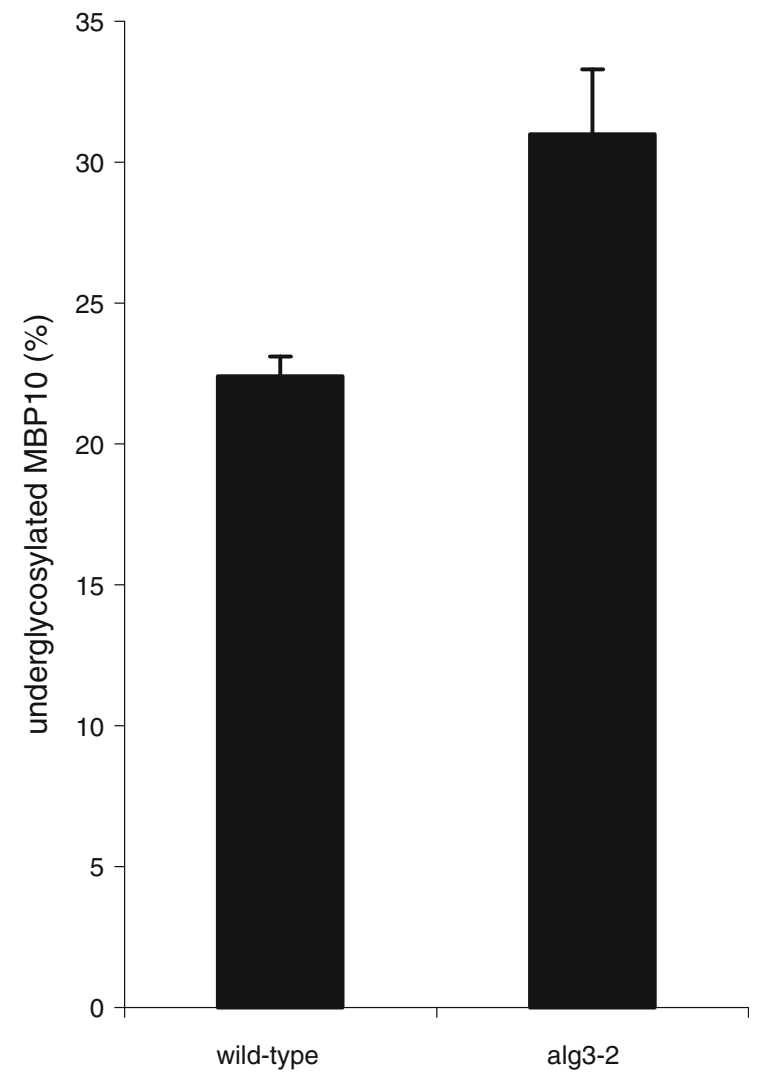

Fig. 3 Level of underglycosylated MBP10 isolated from wildtype and alg3-2 seeds determined by Q-TOF LCMS. MBP10 isolated from total seed protein fractions from wild-type and alg3-2 expressing MBP10 after overnight incubation with PNGase F were analyzed by Q-TOF LC-MS. The ratio of N-D resulting from the PNGase reaction gives the ratio between non- and deglycosylation of MBP10

pathway (aberrant $\mathrm{Man}_{5-3} \mathrm{GlcNAc}_{2}$ type). A similar difference was observed for glycans on PDI in WT and alg3-2 leaf protein extracts (Henquet et al. 2008).

Glycan occupancy of MBP10 dimers from wild type and alg3-2

Since the results show that MBP10 scFv-Fc monomers from both wild type and alg3-2 mutant seeds exist in glycosylated and unglycosylated states, it was of interest to determine the fraction MBP10 dimers consisting of homo-glycosylated, hetero-glycosylated and homo-unglycosylated MPB10 scFv-Fc dimers in wild type and alg3-2 seeds. We therefore performed native mass spectrometric analysis on intact $\mathrm{scFv}-\mathrm{Fc}$ dimers (Heck 2008). The mass difference between 


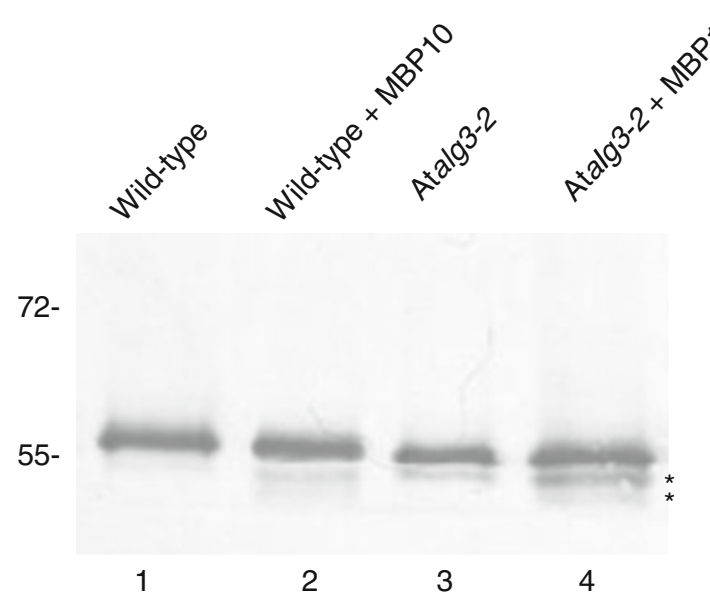

Fig. 4 PDI in wild-type and alg3-2 seeds with or without MBP10 expression Western blot analysis of PDI in wild-type and alg3-2 seeds with or without MBP10 expression. Proteins were isolated from wild-type and alg3-2 seeds and subjected to immunoblotting with anti-PDI. * indicates under glycosylated PDI protein

the different glycoforms in each of the samples corresponded with the mass of the major $\mathrm{N}$-glycan present on wild type or alg3-2 MBP10 ( $\mathrm{Hex}_{8} \mathrm{Glc}$ $\mathrm{NAc}_{2}$ and $\mathrm{Hex}_{5} \mathrm{GlcNAc}_{2}$, respectively). The results show that MBP10 dimers from both wild type and alg3-2 contain either no, one or two glycans (Table 2; $\mathrm{H} 0, \mathrm{H} 1, \mathrm{H} 2)$. This ratio is close to the theoretical ratio between $\mathrm{H} 0: \mathrm{H} 1: \mathrm{H} 2$ based on dimerisation of unglycosylated and glycosylated chains in a random manner, which suggests no preference in dimer formation (Supplemental Table 2).

Binding of MBP10 from wild-type and alg3-2 to the antigen

The Fv of MBP10 contains a binding site to the maltose binding protein (Van Droogenbroeck et al. 2007). We tested whether the affinity of MBP10 to maltose binding protein was affected by the difference in glycan structure on MBP10 in wild type and MBP10 in the alg3-2 mutant plants. Purified MBP10 antibodies from both wild type and alg3-2 were tested for reactivity with maltose binding protein by ELISA for binding against MBP antigen. The results show that MBP10 from alg3-2 has a slightly lower binding affinity for the antigen than MBP10 from wild type seeds at high concentrations but that they are
Table 2 Glycan occupancy on MBP10 dimers (zero glycans: $\mathrm{H} 0$, one glycan: H1, two glycans $\mathrm{H} 2$ ) in wild-type and alg3-2 seeds

\begin{tabular}{lccc}
\hline Sample & $\begin{array}{l}\text { Molecular } \\
\text { mass (Da) }\end{array}$ & $\begin{array}{l}\text { Mass } \\
\text { difference }\end{array}$ & $\begin{array}{l}\text { Expected mass } \\
\text { difference (Da) }\end{array}$ \\
\hline Wild type H0 & 107713.2 & - & - \\
Wild type H1 & 109383.5 & +1670.3 & 1702.0 \\
Wild type H2 & 111080.2 & +1696.7 & 1702.0 \\
alg3-2 H0 & 107666.9 & & - \\
alg3-2 H1 & 108882.6 & +1215.7 & 1216.0 \\
alg3-2 H2 & 110092.0 & +1209.4 & 1216.0 \\
\hline
\end{tabular}

Glycan occupancy was based on the major mass difference between the unglycosylated form $(\mathrm{H} 0)$ and other identified total MPB10 dimer masses. The theoretical molecular weight of unglycosylated MPB10 scFv-Fc dimer (H0): 107584.4 Da. Expected mass difference is based on the most common occurring glycan on MBP10 in wild-type (Hex8GlcNAc2) or alg3-2 (Hex5GlcNAc) (see Table 1

indistinguishable at lower concentrations (Supplemental Fig. 4).

\section{Discussion}

MBP10 expression affects N-glycosylation levels in seeds

Here we have compared the production of the MBP10 antibody in wild type and alg3-2 mutant background. The alg3-2 background has as potential advantage that glycan modifications on ER resident proteins are highly uniform. On MBP10 protein, next to the high level of aberrant Man5GlcNac2 glycan, a low level of normal high mannose type $\mathrm{N}$-glycans was detected, which apparently resulted from leakage of the alg3-2 mutation. (Henquet et al. 2008).

The total amount of complex type $\mathrm{N}$-glycans, as detected by MALDI-TOF, was lower in alg3-2 seeds compared to wild-type (Supplemental Table 1: $43.4 \%$ in alg3-2 compared to $55.9 \%$ in wild-type). In contrast, in leaves the relative level of complex glycosylation was similar for wild-type and the alg32 mutant (Henquet et al. 2008). The difference in level of complex $\mathrm{N}$-glycans between wild type and alg3-2 seed proteins was confirmed by an ELISA assay (Supplemental Fig. 2). The difference could be related to a reduced substrate specificity of $\mathrm{N}$-acetylglucosaminyltransferase I (GnTI) for the 
aberrant $\mathrm{Man}_{3} \mathrm{GlcNAc}_{2} \mathrm{~N}$-glycans which are produced in alg3-2 after trimming of aberrant $\mathrm{N}$-glycan structures by ManI. Indeed, in vitro experiments have shown that, for both plant and mammalian GnTI, both substrates can be used but that $\mathrm{Man}_{5} \mathrm{GlcNAc}_{2}$ is the preferred substrate (Schachter et al. 2003; Strasser et al. 2005). It could be that with the elevated secretion activity in seeds compared to leaves, the GnTI levels in seeds are more limiting than in leaves. Alternatively, or in addition, it could be that the elevated secretion activity in seeds favors sequestering of proteins with aberrant glycans to ER derived protein storage bodies, resulting in diminished transport of endogenous proteins to and through the Golgi.

The levels of accumulate MBP10 protein were similar in alg3-2 and wild type seeds (Fig. 1). However, the production of MBP10 in seeds did affect the glycosylation status of endogenous glycoproteins like PDI (Fig. 4). This effect seems to be stronger in alg3-2 seeds with MBP10 expression than in wild type seeds with MBP10 expression. The results suggest a limit to the $\mathrm{N}$-glycosylation capacity in relation to the elevated protein secretion activity in the ER of developing seeds. In the alg3-2 background, the under glycosylated levels of MBP10 and PDI were even higher, which may be caused by reduced affinity of the oligosaccharyltransferase (OST) complex for lipid bound aberrant type glycans.

\section{Aberrant glycans have no effect on physical} properties of MBP10

The overall binding properties of MBP10 as produced in the alg3-2 background were not much different from those of MBP10 as produced in wild type seeds (Supplemental Fig. 4). Although the binding of MBP10 to the maltose binding protein is not dependent on dimerisation of the antibody, it was of interest to determine whether dimer formation showed preferences for homodimer (fully glycosylated or fully unglycosylated) or heterodimer (one glycosylated and one not glycosylated) formation. Results showed both homodimer and heterodimer antibodies are present. The relative abundance, based on peak intensities of each of the glycoforms, was similar to the predicted abundance based on random associations (Table 2 and Supplemental Table 2), indicating that the difference in glycan structure is of no influence in dimerisation.

\section{Materials and methods}

Plant materials and growth conditions

Seeds of Arabidopsis thaliana lines were sown on $9 \mathrm{~cm} 0.8 \%$ daishin agar Petri dishes and placed in a cold room at $4^{\circ} \mathrm{C}$ for 2 days in the dark to promote uniform germination. Germination and plant culture were performed in a climate chamber $\left(20 / 15^{\circ} \mathrm{C}\right.$ day/ night temperatures; $250 \mu \mathrm{mol}$ light $\mathrm{m}^{-2} \mathrm{~s}^{-1}$ at plant level during $12 \mathrm{~h} /$ day and $75 \%$ relative humidity).

Construction of alg3-2/MBP plants

The alg3-2/MBP plants were obtained by crossing alg3-2 mutant plants with wild-type Col0 plants containing the MBP antibody gene. F2 generation was screened for homozygous alg3-2 T-DNA insertion with PCR on genomic DNA using the forward primer Alg3-F2.2 (5'-CGTTCAGTGATGTATCAG CCTCACGG- $3^{\prime}$ ) and the reverse primer Alg3-R2 (5'-GGATTTAGGGTGTTCTTTGAGCTGATAAG G-3'). Proteins from seeds from homozygous alg3-2 F2 plants were separated on SDS-PAGE gel and stained with Commassie Brilliant blue to select for plants containing the anti-MBP antibody.

\section{SDS-PAGE and immunoblotting}

Plant material was ground in liquid nitrogen, resuspended in $10 \mu \mathrm{l}$ phosphate-buffered saline $(137 \mathrm{mM}$ $\mathrm{NaCl}, 2.7 \mathrm{mM} \mathrm{KCl}, 10 \mathrm{mM} \mathrm{Na} \mathrm{HPO}_{4}, 2 \mathrm{mM} \mathrm{KH}$ $\mathrm{PO}_{4}, \mathrm{pH}$ 7.4) per mg of plant material and centrifuged. An aliquot of the supernatant was immediately mixed with SDS-polyacrylamide gel electrophoresis (PAGE) loading buffer, denatured at $95^{\circ} \mathrm{C}$ for $5 \mathrm{~min}$ and subjected to SDS-PAGE (8 or 12.5\%) under reducing conditions. Protein gel blotting was performed using polyvinylidene difluoride membranes, blocked with $5 \%$ (w/v) nonfat dry milk in Trisbuffered saline $(20 \mathrm{mM}$ Tris-HCl, $\mathrm{pH} 7.6$, and $137 \mathrm{mM} \mathrm{NaCl}$ ) with $0.05 \%$ Tween 20 . The membranes were probed with anti-PDI (1:5000; Rosebiotech). Detection of bound primary antibodies was performed with BCIP/NBT after incubation with goat anti-rabbit antibodies. PNGase $\mathrm{F}$ and Endo $\mathrm{H}$ were purchased from New England Biolabs for glycosylation analysis of PDI and MBP10 and used according to the suggested methods along with the manufacturer's 
recommended buffers. The reactions were terminated by boiling in SDS-loading buffer.

Purification of the MBP10 antibody

MBP10 antibodies were purified from crude seed extracts with a Vivapure Miniprep A kit (Sartorius) according to the manufacturer's protocol.

\section{ELISA}

Microtiter plates were coated with protein extract from seeds overnight at $4^{\circ} \mathrm{C}$ in $0.1 \mathrm{M}$ sodium carbonate buffer, $\mathrm{pH}$ 9.6. The plates were washed with phosphate-buffered saline (PBS) containing $0.05 \%$ Tween 20 and blocked with PBS-T containing $5 \%$ skimmed milk for $1 \mathrm{~h}$ at RT. After the washing the plates were incubated for $1 \mathrm{~h}$ at RT with polyclonal anti-HRP antibody (Sigma) diluted 1:2,000. Detection of bound primary antibodies was performed with AP substrate after incubation with goat anti-rabbit antibodies.

Isolation of $\mathrm{N}$-glycans and $\alpha(1,2)$-mannosidase treatment

Seeds of Arabidopsis plants were used for N-glycans analysis. Proteins for $\mathrm{N}$-glycan purification were extracted from $100 \mathrm{mg}$ of seeds and digested with pepsin. Bound N-glycans were released by PNGase A (Roche) as described previously (Bakker et al. 2006). Aspergillus satoi $\alpha(1,2)$-mannosidase $(10 \mathrm{mU} / \mathrm{ml}$; Pro-enzyme, Glyko) digestions were performed in the supplied buffer for $24 \mathrm{~h}$ at $37^{\circ} \mathrm{C}$. Reactions were then diluted with $0.5 \mathrm{ml}$ of milliQ water and desalted by passage through a $500 \mathrm{mg} \mathrm{C} 18$ column (Varian).

\section{$\mathrm{N}$-glycan analysis}

Purified N-glycans were dissolved in $5 \mathrm{mM} \mathrm{NaAc}$ and mixed with an equal volume of $1 \% 2,5-$ dihydroxybenzoic acid in 50\% acetonitrile. Onemicroliter aliquots were spotted onto a stainless-steel sample plate and dried under a stream of air at room temperature. Positive-ion MALDI-TOF spectra of $[\mathrm{M}+\mathrm{Na}]+$ adducts were recorded on an Ultraflex mass spectrometer (Bruker, Billerica, MA) fitted with delayed extraction and a nitrogen laser $(337 \mathrm{~nm})$. A maltodextrin series was used as an external molecular weight standard. Spectra were generated from the sum of at least 1,000 laser pulses.

MALDI glycopeptide analysis

The protein A purified MBP10 protein from both wild type and alg3-2 was isolated from a reducing denaturing SDS-PAGE gel, treated with trypsin and the peptide mixture was desalted using C18 zip-tip (Millipore). The purified (glyco)peptide mixture was dissolved in milliQ water and spotted onto a stainlesssteel MALDI target plate. Samples spotted onto MALDI plate were overlaid with an equal volume of dihydroxybenzoic acid (DHB, $2 \mathrm{mg} / \mathrm{ml} 30 \%$ ACN with $0.1 \%$ TFA) and allowed to dry in air at room temperature. Positive-ion MALDI-TOF spectra were recorded on an Ultraflex mass spectrometer (Bruker, Billerica, MA) fitted with delayed extraction and a nitrogen laser $(337 \mathrm{~nm})$. A maltodextrin series was used as an external molecular weight standard. Spectra were generated from the sum of at least 1,000 laser pulses. The glycans on the glycopeptides were subsequently deduced by subtracting the mass of the predicted tryptic scFv-Fc peptide (EEQYNSTYR; $1188.5 \mathrm{Da}$ ) from the observed masses of the glycopeptides.

\section{Native mass spectrometry}

The buffers of the proteins were exchanged to $100 \mathrm{mM}$ ammonium acetate $\mathrm{pH} 7.5$, using ultrafiltration units with a cutoff of 10,000 Da (Millipore, Bedford, USA). All antibodies were analyzed at a concentration of $5 \mu \mathrm{M}$. Electrospray ionization capillaries were prepared in house as described previously (van den Heuvel et al. 2006). Analysis was performed on an LCT in positive ion mode (Waters, UK). Typically mass spectra were recorded with a capillary voltage of $1.2 \mathrm{kV}$ and a cone voltage of $200 \mathrm{~V}$. The pressure in the source region was raised to approximately $7 \mathrm{mbar}$, the pressure in the ToF was $2.7 \times 10^{-6}$ mbar. All spectra were calibrated using a solution of $25 \mathrm{mg} / \mathrm{ml}$ cesium iodide in MilliQ water.

Acknowledgments We thank Ngoc Tram Hong, Marieke Mastop, Elise Vendeuvre, Tulipan Zollinger, Adrie Westphale, Bart van Droogenbroeck and Geert de Jaeger for their useful comments and contribution to experiments. This work was supported by the Netherlands Proteomics Centre, the Graduate School "Experimental Plant Sciences," the Centre for 
Biosystems Genomics (Netherlands Genomics Initiative). This collaboration was in part supported by Cost Action FA0804: "Molecular farming: plants as a production platform for high value proteins".

Open Access This article is distributed under the terms of the Creative Commons Attribution Noncommercial License which permits any noncommercial use, distribution, and reproduction in any medium, provided the original author(s) and source are credited.

\section{References}

Bakker H, Bardor M, Molthoff JW, Gomord V, Elbers I, Stevens LH, Jordi W, Lommen A, Faye L, Lerouge P, Bosch D (2001) Galactose-extended glycans of antibodies produced by transgenic plants. Proc Natl Acad Sci USA 98(5): 2899-2904

Bakker H, Rouwendal GJ, Karnoup AS, Florack DE, Stoopen GM, Helsper JP, van Ree R, van Die I, Bosch D (2006) An antibody produced in tobacco expressing a hybrid beta-1, 4-galactosyltransferase is essentially devoid of plant carbohydrate epitopes. Proc Natl Acad Sci USA 103(20):7577-7582

Bardor M, Loutelier-Bourhis C, Paccalet T, Cosette P, Fitchette AC, Vezina LP, Trepanier S, Dargis M, Lemieux R, Lange C, Faye L, Lerouge P (2003) Monoclonal C5-1 antibody produced in transgenic alfalfa plants exhibits a $\mathrm{N}$-glycosylation that is homogenous and suitable for glyco-engineering into human-compatible structures. Plant Biotechnol J 1(6):451-462

Bencurova M, Hemmer W, Focke-Tejkl M, Wilson IB, Altmann F (2004) Specificity of IgG and IgE antibodies against plant and insect glycoprotein glycans determined with artificial glycoforms of human transferrin. Glycobiol 14(5):457-466

Castilho A, Strasser R, Stadlmann J, Grass J, Jez J, Gattinger P, Kunert R, Quendler H, Pabst M, Leonard R, Altmann F, Steinkellner H (2010) In planta protein sialylation through overexpression of the respective mammalian pathway. J Biol Chem 285(21):15923-15930

Cox KM, Sterling JD, Regan JT, Gasdaska JR, Frantz KK, Peele CG, Black A, Passmore D, Moldovan-Loomis C, Srinivasan M, Cuison S, Cardarelli PM, Dickey LF (2006) Glycan optimization of a human monoclonal antibody in the aquatic plant Lemna minor. Nat Biotechnol 24(12): 1591-1597

Fischer R, Emans N (2000) Molecular farming of pharmaceutical proteins. Transgenic Res 9(4-5):279-299 (discussion 277)

Fischer R, Hoffmann K, Schillberg S, Emans N (2000) Antibody production by molecular farming in plants. J Biol Regul Homeost Agents 14(2):83-92

Fujiyama K, Palacpac NQ, Sakai H, Kimura Y, Shinmyo A, Yoshida T, Seki T (2001) In vivo conversion of a glycan to human compatible type by transformed tobacco cells. Biochem Biophys Res Commun 289(2):553-557
Giddings G (2001) Transgenic plants as protein factories. Curr Opin Biotechnol 12(5):450-454

Heck AJ (2008) Native mass spectrometry: a bridge between interactomics and structural biology. Nat Method 5(11):927-933

Henquet M, Lehle L, Schreuder M, Rouwendal G, Molthoff J, Helsper J, van der Krol S, Bosch D (2008) Identification of the gene encoding the alpha1, 3-mannosyltransferase (ALG3) in Arabidopsis and characterization of downstream n-glycan processing. Plant Cell 20(6):1652-1664

Huether CM, Lienhart O, Baur A, Stemmer C, Gorr G, Reski R, Decker EL (2005) Glyco-engineering of moss lacking plant-specific sugar residues. Plant Biol (Stuttg) 7(3):292-299

Ko K, Tekoah Y, Rudd PM, Harvey DJ, Dwek RA, Spitsin S, Hanlon CA, Rupprecht C, Dietzschold B, Golovkin M, Koprowski H (2003) Function and glycosylation of plantderived antiviral monoclonal antibody. Proc Natl Acad Sci USA 100(13):8013-8018

Misaki R, Kimura Y, Palacpac NQ, Yoshida S, Fujiyama K, Seki T (2003) Plant cultured cells expressing human beta1, 4-galactosyltransferase secrete glycoproteins with galactose-extended N-linked glycans. Glycobiol 13(3):199-205

Palacpac NQ, Yoshida S, Sakai H, Kimura Y, Fujiyama K, Yoshida T, Seki T (1999) Stable expression of human beta1, 4-galactosyltransferase in plant cells modifies Nlinked glycosylation patterns. Proc Natl Acad Sci USA 96(8):4692-4697

Peeters K, De Wilde C, De Jaeger G, Angenon G, Depicker A (2001) Production of antibodies and antibody fragments in plants. Vaccine 19(17-19):2756-2761

Rayon C, Lerouge P, Faye L (1998) The protein N-glycosylation in plants. J Exp Bot 49(326):1463-1472

Schachter H, Reck F, Paulsen H (2003) Use of synthetic oligosaccharide substrate analogs to map the active sites of $\mathrm{N}$-acetylglucosaminyltransferases I and II. Methods Enzymol 363:459-475

Staub JM, Garcia B, Graves J, Hajdukiewicz PT, Hunter P, Nehra N, Paradkar V, Schlittler M, Carroll JA, Spatola L, Ward D, Ye G, Russell DA (2000) High-yield production of a human therapeutic protein in tobacco chloroplasts. Nat Biotechnol 18(3):333-338

Stoger E, Vaquero C, Torres E, Sack M, Nicholson L, Drossard J, Williams S, Keen D, Perrin Y, Christou P, Fischer R (2000) Cereal crops as viable production and storage systems for pharmaceutical scFv antibodies. Plant Mol Biol 42(4):583-590

Strasser R, Stadlmann J, Svoboda B, Altmann F, Glossl J, Mach L (2005) Molecular basis of N-acetylglucosaminyltransferase I deficiency in Arabidopsis thaliana plants lacking complex N-glycans. Biochem J 387(Pt 2):385-391

Strasser R, Stadlmann J, Schahs M, Stiegler G, Quendler H, Mach L, Glossl J, Weterings K, Pabst M, Steinkellner H (2008) Generation of glyco-engineered Nicotiana benthamiana for the production of monoclonal antibodies with a homogeneous human-like N-glycan structure. Plant Biotechnol J 6(4):392-402

Strasser R, Castilho A, Stadlmann J, Kunert R, Quendler H, Gattinger P, Jez J, Rademacher T, Altmann F, Mach L, 
Steinkellner H (2009) Improved virus neutralization by plant-produced anti-HIV antibodies with a homogeneous beta1, 4-galactosylated N-glycan profile. J Biol Chem 284(31):20479-20485

van den Heuvel RH, van Duijn E, Mazon H, Synowsky SA, Lorenzen K, Versluis C, Brouns SJ, Langridge D, van der Oost J, Hoyes J, Heck AJ (2006) Improving the performance of a quadrupole time-of-flight instrument for macromolecular mass spectrometry. Anal Chem 78(21): 7473-7483

Van Droogenbroeck B, Cao J, Stadlmann J, Altmann F, Colanesi S, Hillmer S, Robinson DG, Van Lerberge E, Terryn N, Van Montagu M, Liang M, Depicker A, De Jaeger G (2007) Aberrant localization and underglycosylation of highly accumulating single-chain Fv-Fc antibodies in transgenic Arabidopsis seeds. Proc Natl Acad Sci USA 104(4):1430-1435

von Schaewen A, Sturm A, O’Neill J, Chrispeels MJ (1993) Isolation of a mutant Arabidopsis plant that lacks N-acetyl glucosaminyl transferase I and is unable to synthesize Golgi-modified complex N-linked glycans. Plant Physiol 102(4):1109-1118

Wright A, Morrison SL (1998) Effect of C2-associated carbohydrate structure on Ig effector function: studies with chimeric mouse-human IgG1 antibodies in glycosylation mutants of Chinese hamster ovary cells. J Immunol 160(7):3393-3402 